\title{
Development of the Guernsey Community Participation and Leisure
}

Assessment - Revised (GCPLA-R)

\section{Abstract}

A sufficiently psychometrically robust measure of community and leisure participation of adults with intellectual disabilities was not in existence, despite research identifying this as an important outcome and a key contributor to quality of life. The current study aimed to update the Guernsey Community Participation and Leisure Assessment (GCPLA). Adults with intellectual disabilities, carers and experts were consulted in creating a revised pool of 46 items. These were then tested and data from 326 adults with intellectual disabilities were analysed for their component structure and psychometric properties. Principal Component analysis discovered a stable set of components describing seven different clusters. This revised measure (the GCPLA-R) was demonstrated to have satisfactory reliability, and scores were related to challenging behaviour and adaptive behaviour in theoretically consistent ways and were correlated with scores on comparable measures. 


\section{Introduction}

The World Health Organization's (2001) International Classification of Disability and Health (ICF) is a framework for describing and organising information on functioning and disability. It provides a standard language and a conceptual basis for the definition and measurement of health and disability. In the ICF, functioning and disability are multi-dimensional concepts, relating to body functions and structures (impairments), activities, participation or involvement and environmental factors. The ICF definition of participation includes involvement in life situations. Implicit in the ICF framework is that the person may experience activity limitations and participation restrictions that are as a result of an interaction between the impairment and a range of contextual and personal factors. In the ICF, participation is categorised into: learning and applying knowledge; general task and demands; communication; mobility; selfcare; domestic life; interpersonal interactions and relationships; major life areas such as work or school; and community, social, and civic life. Hence participation would encompass both involvement in community and leisure activities. Community and leisure participation are considered separate but overlapping constructs, i.e. community activities can either be leisure or utilitarian based and leisure activities can either be community or indoor based.

It is acknowledged that over time community participation in particular has been a contested and ambiguous concept (Bigby, Anderson \& Cameron, 2018), with a range of caveats such as presence, integration, exposure and inclusion being used to reflect these different perspectives. In addition, current conceptualisations of the broader concept of quality of life increasingly 
emphasise the individual's perception of satisfaction and enjoyment (McDougall, Wright, Schmidt, Miller \& Lowry, 2011). However, participation is a fundamental precursor of inclusion and a prerequisite for subjective evaluation of enjoyment/satisfaction or otherwise. Furthermore, participation as defined by the ICF faces fewer challenges in terms of assessment. Thus, community and leisure participation in the context of this study is considered a multidimensional construct that can be measured by frequency, level and enjoyment.

Research has shown that participation in community and leisure activities by people with intellectual disabilities encourages their inclusion in the community, improves their perception of quality of life (Cummins \& Lau 2003) and contributes to the acquisition of adaptive skills (Law 2002). Conversely, restricted participation creates a barrier to empowerment and selfdetermination, and results in decreased quality of life (e.g. McVilley, Stancliffe, Parmenter \& Burton-Smith, 2006). Moreover, there is consistent evidence that people with intellectual disabilities participate in community and leisure activities less than non-disabled and other disability groups (Verdonschot, de Witte, Reichrath, Buntinx \& Curfs, 2009; Law, 2002, Baker 2007; Ratti et al 2016).

It is generally accepted that policies and procedures should include the facilitation of participation in the daily lives of people with intellectual disabilities (Verdonschot et al., 2009). Taylor-Roberts, Strohmaier, Jones \& Baker (2019), in a systematic review of community participation measures designed for 
people with intellectual disabilities, argued that if services are to be held accountable for the community participation of the people they serve, it is difficult to imagine how this be could be achieved or monitored without an accurate measure. Worryingly, they concluded that all of the measures in their review suffered from concerns in terms of quality and that no valid psychometrically robust measure of level of community participation existed for adults with intellectual disabilities, highlighting the need for the development of such a measure.

The current study was driven by the need to develop an up to date, comprehensive and psychometrically robust measure of the frequency and variety of community participation and leisure activity of people with intellectual disabilities. In particular, it focused on updating and revalidating the Guernsey Community Participation and Leisure Assessment (GCPLA; Baker, 2000). This measure was selected for updating over other measures as it is a broad measure encompassing both community and leisure participation, with TaylorRoberts et al. (2019) finding that the GCPLA had the strongest psychometric properties of the measures they reviewed.

Participation scales can be split into two clusters, with one cluster measuring the frequency and variety of participation, and the other cluster measuring the experience, satisfaction with and impact on wellbeing of participation. Whilst the latter can provide insight into meaning and internal experience, the former can provide quantifiable, standardized information to detect change or compare with other settings/populations (Chang, et al., 2013). The GCPLA was 
intentionally designed to be used as either a structured interview or a by-proxy questionnaire of involvement in community and leisure activities. Whilst the need for measures to account for personal experience of the individuals being assessed was recognised, it was considered vital that a measure be produced that could be used on behalf of a population of individuals whose degree of cognitive impairment would result in them not being able to give an account of their personal experience (Baker, 2000). The GCPLA produces scores in relation to frequency of access and independence. Despite having acceptable internal consistency, reliability, and convergent validity, Taylor-Roberts et al. (2019) reported that no factor analysis was conducted and three of the nine domains of community participation (based on Chang et al.'s, 2013 interpretation of the ICF) were not covered (Assisting Others, Work and Employment, and Political Life and Citizenship). Whilst experts in the field of intellectual disabilities were consulted in its development, people with intellectual disabilities were not. Additionally, the GCPLA was published over 20 years ago at the time of writing and some of the items were considered to be outdated and did not reflect recent innovations and changes in lifestyle, in particular use of the internet and social media.

\section{Aims}

This study aimed to revise the GCPLA to create a measure of community participation and leisure activity that could be used in a variety of contexts with a diverse range of people (adults) with intellectual disabilities. The revised measure would need to be designed as a by proxy measure primarily, in order to also accommodate the needs of individuals with moderate to profound 
intellectual disabilities. The scale would need to demonstrate sufficient reliability and validity.

It was intended that the development of the Guernsey Community Participation and Leisure Assessment - Revised (GCPLA-R) would involve consultation with focus groups, before conducting exploratory analyses of a large pool of items with no predictions or limitations regarding the number or contents of factors that would emerge. Item inclusion in the initial pool would be guided by themes that emerged from the focus groups, as well as the Chang et al (2013) participation domains based on the ICF.

The authors sought to create a measure that would demonstrate: a) good face and content validity through thoughtful consultation and good domain coverage; b) adequate test-retest and inter-rater reliability, along with internal consistency; and c) good construct validity, including multiple reliable factors reflecting distinct aspects of community participation, and a theoretically consistent relationship with measures of adaptive and challenging behaviour. Regarding the latter, it was expected that higher levels of perceived challenging behaviour would be associated with lower scores on the new measure (e.g. Baker, 2000; and as highlighted by Emerson's (1995) definition of challenging behaviour which explicitly refers to denial of access to ordinary community facilities), and that higher levels of adaptive functioning would correlate with higher scores (e.g. Baker, 2000; Chou, Lin, Pu, Lee \& Chang, 2008, Heller, Miller \& Factor, 1998). 
Methods

\section{Design}

Measure revision and revalidation proceeded in stages broadly following the framework of Boateng, Neilands, Frongillo, Melgar-Quiñonez \& Young (2018). In the first phase, items are generated and the validity of their content is assessed. In the second phase, the scale is constructed. In the third phase, scale evaluation, the number of dimensions is tested, reliability is tested, and validity is assessed. This study however combined their second and third stages; i.e. item selection (and hence final scale construction) took place on the same dataset as that on which validation of the measure occurred. As detailed in the discussion, this will need to be consolidated by future research.

Initially, a focus group consultation stage used qualitative methods, taking a discovery-oriented approach to support the revision of existing GCPLA items and the generation of new items. Principal component analysis was then conducted on the pool of items generated in the previous phase to ascertain a component structure and appropriate items for inclusion in a revised GCPLA, and the reliability and validity of the revised measures was examined.

\section{Participants}

The focus group stage included two groups, one for family members, care staff and professionals $(n=6)$ and one for people with intellectual disabilities $(n=9)$. For the psychometric evaluation, 153 individuals with intellectual disabilities (87 men, 66 women) with a mean age of 45.18 years $(S D=13.35$, range $=18-74)$ comprised the preliminary sample; see Table 1 for additional demographic 
information. The supported accommodation services were based across three counties in the south of England and included both rural and urban locations. The services supported individuals with intellectual disabilities ranging from mild to profound. It was not possible to record individuals' levels of intellectual disabilities as this information was not readily available to support staff. A measure developed from the new item pool and was distributed via service managers to keyworkers of the participants in order to fill in on their behalf. Additionally, 30 staff working with people with intellectual disabilities were recruited from five of the services within the supported accommodation provision and asked to volunteer to complete the draft revised version of the GCPLA on themselves, to form a comparison sample. Demographics for this sample were as follows: 15 men and 15 women; mean age of 38.81 years $(\mathrm{SD}=11.24$, range $21-62$, missing data $n=4) ; 24$ White British, 2 White European, 1 White Asian, and 2 missing ethnicity data.

---Table 1, about here please. ---

A further 173 individuals with intellectual disabilities were recruited from national and local independent sector providers of supported living services for adults with intellectual disabilities as part of an extended sample to enable exploration of component structure. A senior service manager in each organisation distributed the measure to key workers in 32 individual service environments within the organisation. In order to ensure anonymity of the participants, no demographic data were collected for this extended sample. 


\section{Ethics}

Canterbury Christ Church University's Salomons Centre research ethics committee granted ethical approval for the initial study, while the University of Kent's Tizard Centre research ethics committee approved data collection for the extended sample. Ethics approval for the initial sample required consent, and an information sheet was given to all participants. Staff members were asked to assess the capacity of the individual with an intellectual disability to give their own informed consent, and to either read through the information sheet (an adapted version) with them and seek their signed consent, or to fill out a consent form on their behalf (if the decision was taken that they did not have the capacity to give their informed consent). Written informed consent was obtained in all cases. Demographic data was unavailable for the second group, thus none of the participants could be identified in order to give individual consent, with the data completely anonymous.

\section{Procedure}

In order to assist the generation of items for the revised measure, two separate focus groups were convened, one with people with intellectual disabilities and one with family members, care staff and professionals. The family members, care staff and professionals were all familiar with using the GCPLA. In this group, participants completed the GCPLA in regard to their own community participation and leisure activities, to aid familiarity and so support a discussion of the GCPLA's shortcomings and ideas for improvement. This focus group was transcribed and key themes were drawn out. The focus group for people with intellectual disabilities took place at a day service and the group consisted of service users. The day service supported a large number of service users 
coming from a variety of different locations in the southeast (rural, urban and suburban). This focus group comprised 9 volunteer participants who were present on the day and was conducted in a room in the day service. In order to get the widest possible representation, the focus group was conducted in an informal manner with an open-door policy. A slide show of picture prompts aided the discussion of each activity covered by the GCPLA. Group members were asked if they did each activity or knew other people who did and if they enjoyed it. When activities did not seem relevant, participants were asked whether this was due to lack of interest or a lack of opportunity. Participants were also asked if any activities were missing. The audio recording of this focus group was unfortunately not clear enough to transcribe. However, the structured nature of the discussion meant that key themes could be extrapolated from the written notes taken during the group.

Following the focus groups, a revised pool of items were drafted and sent to staff and carers for comments. This draft was then further revised before its use during the testing stage of the project. The end result was 46 items that were intended to capture community participation and leisure activities in the general population, as well as in adults with intellectual disabilities. This revision retained 15 of the original items from the GCLPA, with 8 receiving minor amendments in wording (e.g. Attend.......), 8 had additional clarification added (e.g. Adult Education/College), a further 5 combined the original items into one category (e.g. public transport) and nine new items were added. (Table 2). 
The 46-item measure and other standardised measures were administered by sending questionnaire packs to staff who worked closely with the 153 people with intellectual disabilities in the initial sample detailed in the participant section. It was emphasised that the informant must know the person well and be able to make the judgements necessary in regard to the participants participation in community and leisure activities. A number of staff meetings were attended by a member of the research team in order to ensure integrity of implementation and by providing further explanation and answering questions. Managers of each service coordinated the dispersal of questionnaire packs amongst their staff and allocated a service user to each member of staff (to ensure the measures were not completed twice for the same individual). A member of the research team attended two services so as to facilitate interrater reliability testing and oversee test-retest reliability testing. Inter-rater reliability testing was conducted by asking staff to complete the core data pack and then give an additional revised 46 -item form to a colleague who also worked closely with the service user in question. Test-retest data were captured by asking a sub-sample of staff to complete the 46 -item form again, in relation to the same service-user as before, after at least 6 days had elapsed.

A further 173 participants were recruited where only data in relation to the $46-$ item form was collected, in order to enable a sufficient number of participants for investigation of the component structure.

\section{Measures}

\section{Seven-day diary}


In order to assess convergent validity, a simple diary was constructed containing a checklist of all 46 items., An opportunistic sample of 14 members of staff, who were designated keyworkers for the participants from five of the services within the supported accommodation service, were asked to record their participant's frequency of engagement in each activity as they occurred over a seven-day period.

\section{The Shortened Adaptive Behaviour Scale}

The Shortened Adaptive Behaviour Scale (SABS; Hatton et al., 2001) is a 24item short form of the 73-item Adaptive Behaviour Scale Residential and Community (Part 1) (ABS-RC2; Nihira, Leland \& Lambert, 1993a; 1993b). Part 1 of the longer form of the measure is "designed to evaluate coping skills considered important to personal independence and responsibility in daily living" (Nihira et al., 1993b, pp. 2-3). The SABS splits the 24 items into three factors: Factor A (personal self-sufficiency), Factor B (community selfsufficiency) and Factor C (personal-social responsibility). Hatton et al. (2001) report good internal consistency (alphas of $0.89-0.98$ ), high correlation with full ABS-RC2 Part 1 equivalents ( $r=0.97$ - 0.99), and high levels of agreement between predicted quartile scores and actual full ABS-RC2 Part 1 quartile scores (Kappa 0.75-0.89; percentage agreement 82\%-92\%).

\section{The Aberrant Behaviour Checklist}

The Aberrant Behaviour Checklist (ABC; Aman, Singh, Stewart \& Field, 1985a) was developed to assess treatment effects in people with intellectual disabilities. Since its original publication, the ABC has been used in over 325 studies, and has been translated into more than 30 languages (Aman 2012). The 58-item questionnaire is graded on a four-point scale ( 0 : the behaviour is 
not at all a problem; to 3: it is a very significant problem). Aman et al.'s (1985b) factor analysis yielded five sub-scales (irritability, lethargy, stereotyped behaviour, hyperactivity and inappropriate speech). Aman et al. (1985b) originally reported good internal consistency for each factor (alphas of 0.86 0.94), acceptable inter-rater reliability for each factor (mean $=.63$ ), high testretest reliability ( $r s=0.96-0.99$ ), and moderate agreements between $A B C$ subscales and relevant ABS Part 2 ('Problem Behaviors') domains ( $r s=0.42$ 0.69). Additionally, many researchers have reported satisfactory psychometric properties in more recent years (e.g. Aman et al. 1985b; Rojahn \& Helsel 1991; Marshburn \& Aman 1992; Richman et al. 2013).

\section{The Index of Community Involvement}

The Index of Community Involvement (ICl; Raynes, Pratt and Roses, 1979) is a simple informant-report Yes/No checklist of whether 14 activities have been undertaken in the past month. The final item asks whether the person has been on holiday in the past year. Higher total scores indicate greater community participation. The ICI has good face validity and 5/9 ICF domains of community participation are covered (Taylor-Roberts et al. 2019). Reported Cronbach's alphas vary between 0.85 (Raynes \& Sumpton, 1986) and 0.59 (Beadle-Brown, Hutchinson \& Whelton, 2012). The $\mathrm{ICl}$ is simple to use, has been widely reported in research, and has good face validity.

\section{Data Analysis}

Initially, themes from the two focus groups were examined in order to construct a draft pool of items to be used in the next stage of the project. With regard to the subsequently collected, quantitative questionnaire data, for participants with $20 \%$ or more overall missing data, data packs were examined and 
subsequently discarded if two or more filled-out questionnaires contained subscales with $20 \%$ or more missing data (Mazza, Enders \& Ruehlman, 2015). Where only one questionnaire in a data pack contained a sub-scale with more than $20 \%$ missing data, individual questionnaires were excluded from further analysis. Where a questionnaire contained missing data that did not amount to $20 \%$ of a sub-scale, pro-rating was used. Specifically, following the guidance of Taylor and Amir (1994), for the $\mathrm{ICl}$ an intermediate value of 0.5 was assigned where data were missing, as each completed item is either one or zero. For the $A B C$ and the sABS, mean scores were calculated and imputed per participant and per sub-scale (Mazza et al., 2015). For missing data in the draft GCPLA item pool, principal component analysis SPSS's mean substitution procedure was employed. All items bar two had had between $0.6-5.8 \%$ missing items. With play games/computer games (with others), and spectator sport both having $39.3 \%$ missing, this was due to a poorly copied assessment document that was filled in on behalf of 127 participants in one of the provider organisations. See table SI in the online supplementary material for missing item data.

To examine the structure of the newly generated item pool and attempt to create a revised version of the measure, following Fabrigar, Wegener, Strahan's (1999) guidance, a principal component analysis was conducted on the pool items. The components were expected to be related, so an oblique (direct oblimin) rotation was performed. The Kaiser-Meyer-Olkin (KMO) measure exceeded 0.5 and Bartlett's test of sphericity was significant, as required (Field, 2013). Components were retained if they (i) met the KaiserGuttman criterion of having an eigenvalue greater than 1.00, and (ii) had at 
least three items with a loading greater than 0.4 in magnitude, which loaded with a magnitude less than 0.4 onto all other components. Only items that loaded in this manner onto retained components were themselves retained for the GCPLA-R

Internal consistency was examined using Cronbach's alpha, and test-re-test reliability and inter-rater-reliability examined using Pearson's correlations. On occasion, some of the variables included in these analyses had a skewness or kurtosis of magnitude greater than two. Therefore, all these analyses were repeated using Spearman's correlations. Where the Spearman's and Pearson's correlations reached the same significance level and were similar in magnitude, the latter have been reported. The one occasion where there was a material disagreement, has been highlighted in the results. For all measures except the diary, construct validity was examined using Spearman's correlations because the concerns about deviations from normality were more marked, and the two types of correlations more frequently differed. For the diary, Pearson's correlations appeared robust and so were employed. All significance levels are reported two-tailed.

\section{Results}

\section{Focus Groups}

From the two focus, groups three superordinate themes were identified. These were: conceptual discussion points, ease of use of the measure and specific suggestions for items that should be changed, added or deleted from the 
measure. See Table S2 in the online supplementary material for a detailed breakdown of the content of these three themes.

Drawing on these findings from the focus groups, a 46-item pool was developed to explore a range of possible community participation and leisure activities. For each item a definition was provided to aid the raters' understanding of the item; for example, the item 'doctor (GP)' was accompanied by the definition: 'A medical doctor working in the community as distinct from a consultant or specialist based in a hospital'. Items were scored according to the frequency with which they were participated in, on the following scale: $0=$ Never, $1=$ Very occasionally, 2 = Quarterly or more frequently, 3 = Monthly or more frequently, $4=$ Weekly or more frequently, $5=$ Daily or more frequently. Feedback from the family members, care staff and professionals was that the scoring of the GCPLA should be simplified and that the rating of independence of access was rarely used. Thus, the GCPLA-R scores was derived from simply summating the scores from each item and the supervision rating removed.

\section{Principal component analysis}

The principal component analysis was conducted on the full sample $(N=326)$ and produced 16 components that exceeded the Kaiser-Guttman criterion of eigenvalues greater than 1.00 , and that together explained $63.6 \%$ of the variance. Of these, seven components were retained by virtue of having at least three items with a loading greater than 0.4 in magnitude, and whose loading onto all other components was below this threshold. The retained components and the final set of items, and their loadings, are shown in Table 
3 , while the variance explained by retained component is provided in Table 4 . Note that the negative item loadings in the principal components 4 and 5 ran in the opposite direction to the total score, but since the contributing items ran in the same direction as the total score and all the included items have a response scale that operates in the same direction, they did not need to be reverse scored. As such, there were no implications of the negative loadings for calculating the subscale scores or total score.

---Tables 3 and 4, about here please. ---

\section{Component Structure}

The seven retained components were interpretable as follows. Component 1 contained items relating to enrichment, for example 'attend museum/art gallery'. Component 2 comprised items concerning active leisure pursuits, such as 'swimming' and 'exercise class'. Component 3 concerned social engagement and included items such as 'social networking via the internet' and 'spend time with family'. Component 4 contained items relating to indoor leisure, for example 'look at books / magazines etc.'. Component 5 was made up of items describing social leisure activities, for instance 'disco / nightclub'. Component 6 concerned health related activities, with items such as 'hospital' and 'dentist'. Finally, Component 11 captured retail activities, such as 'high street store'. Components 7 to 10 , and 12 to 16 , did not meet the item loading requirements for inclusion, detailed above.

The items that were excluded from the item pool were omitted on the basis that they did not meet the criteria of loading greater than 0.4 in magnitude on a 
retained component, while loaded with a magnitude less than 0.4 onto all other components. This was generally because items had loadings of less than 0.4 or loaded onto components that were not retained because they had insufficient items.

\section{Internal Consistency}

The GCPLA-R demonstrated satisfactory internal consistency $(\alpha=.75, n=164)$. As can be seen from Table 2, the values of alpha for the seven sub-scales all bar one were 0.6 or above. The lower alphas for the subscales are unsurprising, given that alpha is influenced by the number of items in a scale/sub-scale (Field, 2013).

\section{Test-Retest and Inter-Rater Reliability}

Test-retest reliability was based on a sub-sample of 16 participants and was calculated after an interval of between six days and six weeks, with a mean interval of 15 days. For the same 16 participants, a second rater also completed the GCPLA-R. The test-retest and inter-rater correlation coefficients are provided in Table 4. As can be seen from this table, test-retest reliability was, with overall scores for the majority of the sub-scales. The inter-rater reliability for the overall scores was very close to .7 , but varied from poor to good levels across the sub-scales.

---Table 5, about here please. --- 


\section{Construct Validity}

The correlations between the GCPLA-R overall mean scores and the measures used for validation can be seen in Table 6. From this it can be seen that the GCPLA-R had large, significant, positive correlations with the $\mathrm{ICl}$ and with the equivalent overall mean score from the seven-day diary. In addition, the GCPLA-R showed significant, negative correlations with all bar one of the sub-scales of the Aberrant Behaviour Checklist. Finally, the correlations between the Shortened Adaptive Behaviour Scale's scores were significant and positive, except for one sub-scale that did not achieve significance.

---Table 6, about here please. ---

\section{Comparing GCPLA-R scores for people with and without intellectual disabilities}

The GCPLA-R overall and sub-scale scores for the participants with intellectual disabilities were compared to the scores of a sample of staff members who completed the GCPLA-R on themselves. As can be seen from Table 7, the staff had significantly higher overall means scores, and significantly higher scores on the sub-scales social engagement, indoor leisure, social leisure and retail. The two groups did not significantly differ in their scores on the sub-scales enrichment, active leisure and health.

---Table 7, about here please. ---

\section{Demographic Analyses}

There were no significant differences between male and female participants for the overall mean scores and across all the sub-scale scores $(t(151)<1$, 
p>.37). However, there was a significant negative correlation between participant age and both the overall mean scores $(: r=-.47, p<0.001, n=151)$. This significant, negative correlation with age was found across all the subscales, except for enrichment and health (enrichment: $r=-.02, p=.81, n=151$; health: $r=-.07, \mathrm{p}=.43, n=150)$.

\section{Discussion}

No sufficiently psychometrically robust measure of level of participation in community and leisure activity was in existence for adults with intellectual disabilities. The current research aimed to revise and revalidate the GCPLA. A preliminary stage involved consulting adults with intellectual disabilities, carers and relevant experts, before creating the revised 46 -item pool. The 46 -item scale was then tested and the data relating to 326 adults with intellectual disabilities were analysed to determine its component structure as well as psychometric properties. A stable set of components was uncovered, describing seven different clusters of community participation activities, namely enrichment, active leisure, social engagement, indoor leisure, social leisure, health and retail. The GCPLA-R was produced, containing these seven components and 23 items that loaded on to them. The 23 -item scale was tested for its psychometric properties.

The GCPLA-R showed good construct validity, with mean overall scores correlating with other psychological constructs (challenging behaviour and adaptive behaviour) in theoretically consistent ways. Their validity was also supported by the large, significant, positive correlations with the ICI and seven- 
day diary. As would be expected, individuals who did not have an intellectual disability scored significantly higher on the total scores. Furthermore, test-retest reliabilities were satisfactory, as was internal consistency. Inter-rater reliability was more varied, ranging from good to poor. In many cases it was difficult to recruit two independent informants who knew the person sufficiently well and, where there was lack of agreement, this may well have been the cause. This does however underline the importance of informants knowing the person's routines well. No significant differences were found between scores for men and women, and age was negatively correlated with community participation, as might be expected.

The GCPLA-R was assessed using the adapted version of Straus et al.'s (2016) quality assessment framework proposed by Taylor-Roberts et al. (2017). The measure scored one for face validity, one for content validity, one for factor structure, two for internal consistency, two for convergent and discriminant validity, two for floor and ceiling effect, and two for interpretability, generating a total score of 13 . This compares favourably to the rating of 11 earned by the GCPLA, with improvement in scores concerning factor structures and internal consistency, and would make this the highest scoring measure of the scales assessed in Taylor-Roberts et al.'s (2017) systematic review of community participation measures. However, in terms of content validity, GCPLA-R did not include all ICF domains, with Assisting Others, Religion \& Spirituality, Work \& Employment and Political Life \& Citizenship no longer covered. 
It is recommended that the GCPLA-R be used in research and service evaluation, where the focus is on comparison of community and leisure participation amongst groups, or in circumstances where the individual factor scores might prove to be useful. For example, the indoor leisure items could be included or removed to enable a discrete focus on community participation.

\section{Limitations}

Whilst the results of the study are sufficiently robust to encourage further use of the GCPLA-R, there are a number of imitations to this study which need to be considered by potential users of the measure. Only two small focus groups were used in this study suggesting a degree of caution be used in regard to consideration of representativeness. However, the measures of community participation reviewed by Taylor-Roberts et al. (2019) found that relevant experts were rarely consulted in the process of measure development, and people with intellectual disability were only consulted in one case. In addition, the feedback from the participants in the focus group in this study was in general accord with feedback received by other focus groups of people with intellectual disabilities concerned with participation. For example, community and leisure participation (Beart et al., 2001; García Iriarte et al. 2014), educational and vocational participation (Hamilton et al, 2017; García Iriarte et al. 2014) and citizenship (García Iriarte et al. 2014) were all valued by people with intellectual disabilities. The significance of internet and social media use has also been highlighted by individual participants with intellectual disabilities in a study by Chadwick \& Fullwood (2018) who also emphasised the 
relationship between societal and digital exclusion of people with intellectual disabilities.

Whilst the sample of 326 adults with intellectual disabilities was considered to be adequate for the purposes of statistical analysis, a question remains in regard to representativeness, as these individuals were in supported living services and not living at home. In the future, it would be prudent to add participants living at home to the current sample in order to answer questions in regard to representativeness and robustness of the factor structures.

This study combined Boateng et al's (2018) second and third stages; i.e. item selection (and hence final scale construction) took place on the same dataset as that on which validation of the measure occurred. This is not ideal, but is frequently done in studies, especially where there are limited resources. The item 'play games/computer games (with others)' was included in the GCPLA$R$, this particular item had a large percentage of missing data $(39.3 \%)$ this was due to a measurement error on behalf of the service collecting the data and not a reflection of the relevance of that particular item, however, the $n$ was still substantial (198). As such, in future research it would be helpful for the factor structure of the GCPLA-R to be tested in a new sample of data using confirmatory factor analysis.

As with the GCPLA, the GCPLA-R were specifically designed to be used with adults. This was a matter of expediency and the community and leisure activities for adults and children were considered to be significantly different to 
warrant being treated separately, and the development of a similar measure designed for children would be welcome.

This study solely focused on proxy administration and did not attempt to evaluate the use of the GCPLA-R as a self-report measure. Thus, its use in this context remains untested and any data generated by such use be treated with caution, and an additional evaluation of the psychometric properties of the measure when used in this manner is required.

Finally, the GCPLA-R is not meant to be used as a surrogate measure of quality of life. Whilst there are strong arguments that participation in community and leisure activities are important, they are not synonymous with quality of life. Bigby, Anderson \& Cameron (2018) argue in regard to community participation that it is not "unambiguously virtuous" (Bates \& Davis, 2004; p. 201) and more attention needs to be given to choice and the subjective aspects of participation.

\section{Conclusion}

A psychometrically robust measure of the level of community and leisure participation was needed in order that services could identify individuals requiring further support, and so that needs did not go unmet. The GCPLA-R has emerged as psychometrically a strong measure of community and leisure participation. Comprising 23 items identified in collaboration with service users and relevant experts, it has been demonstrated to have strong face validity and satisfactory internal consistency and reliability. Scores on the GCPLA-R relate to other psychological constructs in ways that are consistent with theory and 
are correlated with scores on comparable measures along with seven components that emerged from a principal component analysis. Content validity was adequate, covering five of Chang's (2013) domains of community participation. Future clinicians and researchers will be enabled to interpret GCPLA-R subscale scores as well as a total score, allowing a richer understanding of individual profiles of community and leisure participation and their contribution to quality of life.

Copies of the scale can be obtained directly from the corresponding author.

\section{References}

Aman M. G., Singh N. N., Stewart A. W. \& Field C. J. (1985a) The aberrant behavior checklist: a behaviour rating scale for the assessment of treatment effects. American Journal of Mental Deficiency 89(5), 485491. https://doi.org/10.1037/t10453-000

Aman, M. G., Singh, N. N., Stewart, A. W., \& Field, C. J. (1985b).

Psychometric characteristics of the aberrant behavior checklist. American journal of mental deficiency, 89(5), 492-502. https://doi.org/10.1037/t10453-000

Aman, M. G. (2012). Aberrant Behavior Checklist: Current identity and future developments. Clinical \& Experimental Pharmacology, 2(3), 21611459. https://doi.org/10.4172/2161-1459.1000e114 
Baker, P. A. (2000). Measurement of community participation and use of leisure by service users with intellectual disabilities: The Guernsey Community Participation and Leisure Assessment (GCPLA). Journal of Applied Research in Intellectual Disabilities, 13(3), 169-185. https://doi.org/10.1046/j.1468-3148.2000.00015.x

Baker, P. A. (2007). Individual and service factors affecting deinstitutionalization and community use of people with intellectual disabilities. Journal of Applied Research in Intellectual Disabilities, 20(2), 105-109. https://doi.org/10.1111/j.1468$\underline{3148.2006 .00313 . x}$

Bates, P., \& Davis, F. A. (2004). Social capital, social inclusion and services for people with learning disabilities. Disability \& Society, 19(3), 195207. https://doi.org/10.1080/0968759042000204202

Beadle-Brown, J., Hutchinson, A., \& Whelton, B. (2012). Person-Centred Active Support-Increasing Choice, Promoting Independence and Reducing Challenging Behaviour. Journal of Applied Research in Intellectual Disabilities, 25(4),291-307.https://doi.org/10.1111/j.14683148.2011.00666.x

Beart, S., Hawkins, D., Kroese, B. S., Smithson, P., \& Tolosa, I. (2001). Barriers to accessing leisure opportunities for people with learning 
disabilities. British Journal of Learning Disabilities, 29(4), 133-138. https://doi.org/10.1046/j.1468-3156.2001.00109.x

Bigby, C., Anderson, S., \& Cameron, N. (2018). Identifying conceptualizations and theories of change embedded in interventions to facilitate community participation for people with intellectual disability: A scoping review. Journal of Applied Research in Intellectual Disabilities, 31(2), 165-180. https://doi.org/10.1111/jar.12390

Boateng, G. O., Neilands, T. B., Frongillo, E. A., Melgar-Quiñonez, H. R., \& Young, S. L. (2018). Best practices for developing and validating scales for health, social, and behavioral research: a primer. Frontiers in public health, 6, 149. https://doi.org/10.3389/fpubh.2018.00149

Chadwick, D. D., \& Fullwood, C. (2018). An online life like any other: Identity, self-determination, and social networking among adults with intellectual disabilities. Cyberpsychology, Behavior, and Social Networking, 21(1), 56-64. https://doi.org/ 10.1089/cyber.2016.0689

Chang, F. H., Coster, W. J., \& Helfrich, C. A. (2013). Community participation measures for people with disabilities: a systematic review of content from an international classification of functioning, disability and health perspective. Archives of physical medicine and rehabilitation, 94(4), 771-781. https://doi.org/10.1016/j.apmr.2012.10.031 
Chou, Y. C., Lin, L. C., Pu, C. Y., Lee, W. P., \& Chang, S. C. (2008).

Outcomes and costs of residential services for adults with intellectual disabilities in Taiwan: A comparative evaluation. Journal of Applied Research in Intellectual Disabilities, 21(2), 114-125. https://doi.org/10.1111/j.1468-3148.2007.00373.x

Cummins, R. A., \& Lau, A. L. (2003). Community integration or community exposure? A review and discussion in relation to people with an intellectual disability. Journal of applied research in intellectual disabilities, 16(2), 145-157. https://doi.org/10.1046/j.14683148.2003.00157.x

Emerson, E. (1995). Challenging behaviour: Analysis and intervention in people with learning disabilities. Cambridge University Press, 40 West 20th Street, New York, NY 10011-4211.

Fabrigar, L. R., Wegener, D. T., MacCallum, R. C., \& Strahan, E. J. (1999). Evaluating the use of exploratory factor analysis in psychological research. Psychological methods, 4(3), 272. https://doi.org/10.1037/1082-989X.4.3.272

Field, A. (2013). Discovering statistics using IBM SPSS statistics (4th ed.). London: Sage.

García Iriarte, E., O'Brien, P., McConkey, R., Wolfe, M., \& O'Doherty, S. (2014). Identifying the Key Concerns of I rish Persons with Intellectual 
Disability. Journal of Applied Research in Intellectual Disabilities, 27(6), 564-575. https://doi.org/10.1111/jar.12099

Hatton, C., Emerson, E., Robertson, J., Gregory, N., Kessissoglou, S., Perry, J., Felce, D., Lowe, K., Walsh, P.N., Linehan, C. and Hillery, J., 2001. The adaptive behavior scale-residential and community (part I): towards the development of a short form. Research in developmental disabilities, 22(4),273-288.https://doi.org/10.1016/S08914222(01)00072-5.

Hamilton, L. G., Mesa, S., Hayward, E., Price, R., \& Bright, G. (2017). 'There's a lot of places l'd like to go and things l'd like to do': the daily living experiences of adults with mild to moderate intellectual disabilities during a time of personalised social care reform in the United Kingdom. Disability \& Society, 32(3), 287-307. https://doi.org/10.1080/09687599.2017.1294049

Heller, T., Miller, A. B., \& Factor, A. (1998). Environmental characteristics of nursing homes and community-based settings, and the well-being of adults with intellectual disability. Journal of Intellectual Disability Research, 42(5), 418-428. https://doi.org/10.1046/j.1365-

2788.1998.00155.x

Law, M. (2002). Participation in the occupations of everyday life. American journal of occupational therapy, 56(6), 640-649. https://doi.org/10.5014/ajot.56.6.640 
Marshburn, E. C., \& Aman, M. G. (1992). Factor validity and norms for the Aberrant Behavior Checklist in a community sample of children with mental retardation. Journal of autism and developmental disorders, 22(3), 357-373. https://doi.org/10.1007/BF01048240

Mazza, G. L., Enders, C. K., \& Ruehlman, L. S. (2015). Addressing item-level missing data: A comparison of proration and full information maximum likelihood estimation. Multivariate behavioral research, 50(5), 504-519. https://doi.org/10.1080/00273171.2015.1068157

McDougall, J., Wright, V., Schmidt, J., Miller, L., \& Lowry, K. (2011). Applying the ICF framework to study changes in quality-of-life for youth with chronic conditions. Developmental Neurorehabilitation, 14(1), 41-53. https://doi.org/10.3109/17518423.2010.521795

McVilly, K. R., Stancliffe, R. J., Parmenter, T. R., \& Burton-Smith, R. M. (2006). 'I Get by with a Little Help from my Friends': Adults with Intellectual Disability Discuss Loneliness 1. Journal of Applied Research in Intellectual Disabilities, 19(2), 191-203. https://doi.org/10.1111/j.1468-3148.2005.00261.x 
Nihira, K., Leland, H., \& Lambert, N. (1993a). Adaptive behavior scaleresidential and community (second edition): examination booklet. Austin, TX: PRO-ED.

Nihira, K., Leland, H., \& Lambert, N. (1993b). AAMR adaptive behavior scaleresidential and community (second edition): examiner's manual. Austin, TX: PRO-ED.

Ratti, V., Hassiotis, A., Crabtree, J., Deb, S., Gallagher, P., \& Unwin, G. (2016). The effectiveness of person-centred planning for people with intellectual disabilities: A systematic review. Research in Developmental Disabilities, 57, 63-84. https://doi.org/10.1016/j.ridd.2016.06.015

Raynes, N. V., Pratt, M. W., \& Roses, S. (1979). Organisational structure and the care of the mentally retarded.

Raynes, N. V. \& Sumpton, R.C. (1986). Follow up study of 448 people who are mentally handicapped. Final report to the DHSS. Manchester, The University, Department of Social Policy.

Richman, D. M., Barnard-Brak, L., Bosch, A., Thompson, S., Grubb, L., \& Abby, L. (2013). Predictors of self-injurious behaviour exhibited by individuals with autism spectrum disorder. Journal of Intellectual 
Disability Research,57(5),429-439.https://doi.org/10.1111/j.13652788.2012.01628.x

Rojahn, J., \& Helsel, W. J. (1991). The Aberrant Behavior Checklist with children and adolescents with dual diagnosis. Journal of Autism and DevelopmentalDisorders, 21(1),17-28.

https://doi.org/10.1007/BF02206994

Taylor, M. A., \& Amir, N. (1994). The problem of missing clinical data for research in psychopathology: some solution guidelines. The Journal of nervous and mental disease, 182(4), 222-229.

https://doi.org/10.1097/00005053-199404000-00006

Taylor-Roberts, L., Strohmaier, S., Jones, F., \& Baker, P. (2019). A systematic review of community participation measures for people with intellectual disabilities. Journal of Applied Research in Intellectual Disabilities, 32(3), 706-718. https://doi.org/10.1111/jar.12565

Schalock, R. L., Verdugo, M. A., \& Braddock, D. L. (2002). Handbook on quality of life for human service practitioners. Washington, DC: American Association on Mental Retardation.

Verdonschot, M. M., De Witte, L. P., Reichrath, E., Buntinx, W. H. E., \& Curfs, L. M. (2009). Community participation of people with an intellectual disability: a review of empirical findings. Journal of Intellectual Disability 
Research, 53(4), 303-318. https://doi.org/10.1111/j.1365-

2788.2008.01144.x

World Health Organization. (2001). International Classification of Functioning, Disability and Health: ICF. World Health Organization. 
Table 1: Gender, ethnicity and age information of preliminary sample $(n=153)$

\begin{tabular}{ll}
\hline Variable & $\mathbf{n}(\%)$ \\
\hline Gender & $66(43.1)$ \\
Female & $87(56.9)$ \\
Male & \\
Self-Reported Ethnicity & $147(96.1)$ \\
White British & $4(2.6)$ \\
White European & $2(1.3)$ \\
Mixed White/Asian & \\
Age & \\
$18-24$ & $66(4.3)$ \\
$25-44$ & $62(41.1)$ \\
$45-64$ & $15(9.9)$ \\
$65+$ & \\
\hline
\end{tabular}




\begin{tabular}{ll}
\hline Original GCPLA items & 46 item Pool \\
\hline Doctor (GP) & Doctor (GP)* \\
Dentist & Dentist* \\
Hospital & Hospital* \\
Police & Work (paid or voluntary) \\
Bus & Adult education/College \\
Train & Look at books/magazines etc* \\
Taxi & Play games/computer games (with others)* \\
Boat & Play games/computer games (solitary)* \\
Aeroplane & Watch TV \\
Craft & Watch DVD \\
Games & Browse internet* \\
T.V. & Interact with pets/animals \\
Videos & Participate in sports* \\
Music (Listen) & Spectator sport \\
Music (Play) & Exercise class* \\
Pets & Cycling \\
Fair/Fete/Festival & Listen to music/radio \\
Museum/Art Gallery & Participate in performing arts/music \\
Sport (Participation) & Create art/activity \\
Sport (Spectator) & Attend museum/art gallery* \\
Exercise/Aerobic Class & Attend live performing arts* \\
Cycling & Attend cinema* \\
Cinema & Go for a walk (local) \\
Theatre & Outdoor pursuits \\
Concert & Holiday or daytrip* \\
Park & Swimming* \\
Beach & DIY \\
Walking & Gardening \\
Holiday & Disco/nightclub* \\
Swimming & Pub \\
Sailing & Restaurant/Cafe* \\
DIY & Go to a friend's house* \\
Gardening & Spend time with family* \\
Disco & Social club/ society* \\
Pub & Social networking via internet* \\
Party & Help others \\
Restaurant/Cafe & Citizenship/Political activity \\
Friend's House & Public transport \\
Neighbour's Home & Local shop/Post office* \\
Social Club (Integrated) & High Street store* \\
Social Club (Segregated) & Supermarket/Large retail outlet* \\
Local Shop & Car boot/Jumble sale \\
High Street Store & Hairdresser/Beauty salon \\
Post Office & Bank/Building Society \\
Hairdresser & Place of worship \\
Supermarket & \\
Chemist & \\
Bank/Building Society & \\
Place of Worship & \\
Large Retail Outlet & \\
Jumble/Car Boot Sale & \\
Library & \\
Adult Education & \\
& \\
\hline & \\
\hline
\end{tabular}

Table 2 GCPLA and the 46 pool items

* Items included in the GCPLA-R 
Table 3. The component loading from the principal component analysis, for the components that were retained, and the associated Cronbach's alphas $(n=326)$.

Component, Items

1

$4 \quad 6$

Component 1: Enrichment $(\alpha=.58)$

Attend museum/art gallery

0.80

Attend live performing arts

Holiday or daytrip

0.50

\section{Component 2: Active leisure $(\alpha=.68)$}

Swimming

Participate in sport

Exercise class

Participate in performing arts/music
0.80

0.69

0.59

0.50

\section{Component 3: Social engagement $(\alpha=.60)$}

Social networking via the internet

Browse internet

Spend time with family

0.54

\section{Component 4: Indoor leisure $(\alpha=.60) *$}

Play games with others

Play solitary games

Look at books / magazines etc.

$-0.64$

\section{Component 5: Social leisure $(\alpha=.63)$ *}

Social club / society

Disco / nightclub

Go to a friend's house

$-0.46$

\section{Component 6: Health $(\alpha=.60)$}

Hospital

$\operatorname{Doctor}(G P)$

Dentist

Component 11: Retail $(\alpha=.80)$

High street store 
Supermarket / large retail outlet

Local shop / post office

* The negative item loadings indicate that in the statistical model, principle components 4 and 5 ran in the opposite direction to the total score, but since the contributing items ran in the same direction as the total score, they did not need to be reverse scored. 
Table 4. Variance explained by retained components $(n=326)$

\begin{tabular}{llll}
\hline $\begin{array}{l}\text { Component } \\
\text { Number }\end{array}$ & \multicolumn{3}{l}{ Initial Eigenvalues and Extraction Sums of Squared Loadings } \\
\hline 1 & Total & \% of Variance & Cumulative \% \\
2 & 5.737 & 12.472 & 12.472 \\
3 & 3.379 & 7.345 & 19.818 \\
4 & 2.562 & 5.570 & 25.388 \\
5 & 1.894 & 4.117 & 29.506 \\
6 & 1.747 & 3.797 & 33.302 \\
11 & 1.646 & 3.579 & 36.881 \\
\hline
\end{tabular}


Table 5: Test re-test and inter-rater reliability correlation coefficients (Pearson's $r)(n=16)$.

\begin{tabular}{lll}
\hline Scale / sub-scale & Test retest $r$ & Inter-rater $r$ \\
\hline Enrichment & $.61^{*}$ & .24 \\
Active leisure & $.95^{* *}$ & $.63^{* *}$ \\
Social engagement & $.93^{* *}$ & $.85^{* *}$ \\
Indoor leisure & $.69^{* *}$ & $.54^{*}$ \\
Social leisure & $.94^{* *}$ & $.67 * *$ \\
Health & $.76^{* *}$ & .13 \\
Retail & $.85^{* *}$ & $.80 \dagger$ \\
\hline Mean score & $.91^{* *}$ & $.69 * *$
\end{tabular}

${ }^{*} \mathrm{p}<0.05, * * \mathrm{p}<0.01$, this Pearson's correlation should be treated with caution as the equivalent Spearman's correlation was substantially different in terms of magnitude and significance. 
Table 6: Correlations between the overall mean scores on the GCPLA-R and the other measures given.

For the diary, Pearson's correlation was employed. For the other measures, Spearman's was used.

\begin{tabular}{lc}
\hline Measure $(n)$ & $.638^{*}$ \\
\hline Seven day diary $(n=14)$ & $.634^{* *}$ \\
ICI $(n=79)$ & -.101 \\
ABC Irritability $(n=153)$ & $-.259^{* *}$ \\
ABC Lethargy $(n=153)$ & -.111 \\
ABC Stereotyped Behaviour $(n=153)$ & -.087 \\
ABC Hyperactivity $(n=153)$ & -.108 \\
ABC Inappropriate Speech $(n=153)$ & .115 \\
SABS Personal Self-Sufficiency $(n=149)$ & $.179 *$ \\
SABS Community Self-Sufficiency $(n=149)$ & $.252^{* *}$ \\
SABS Personal Social Responsibility $(n=149)$ & .155 \\
SABS Total $(n=153)$ & \\
\hline
\end{tabular}

$* \mathrm{p}<0.05, * * \mathrm{p}<0.01, \mathrm{ICI}=$ Index of Community Involvement, $\mathrm{ABC}=$ Aberrant Behaviour Checklist, $\mathrm{SABS}=$ Shortened Adaptive Behaviour Scale 
Table7: A comparison of the GCPLA-R overall and sub-scale scores for the participants with intellectual disabilities with a sample of care staff without intellectual disabilities.

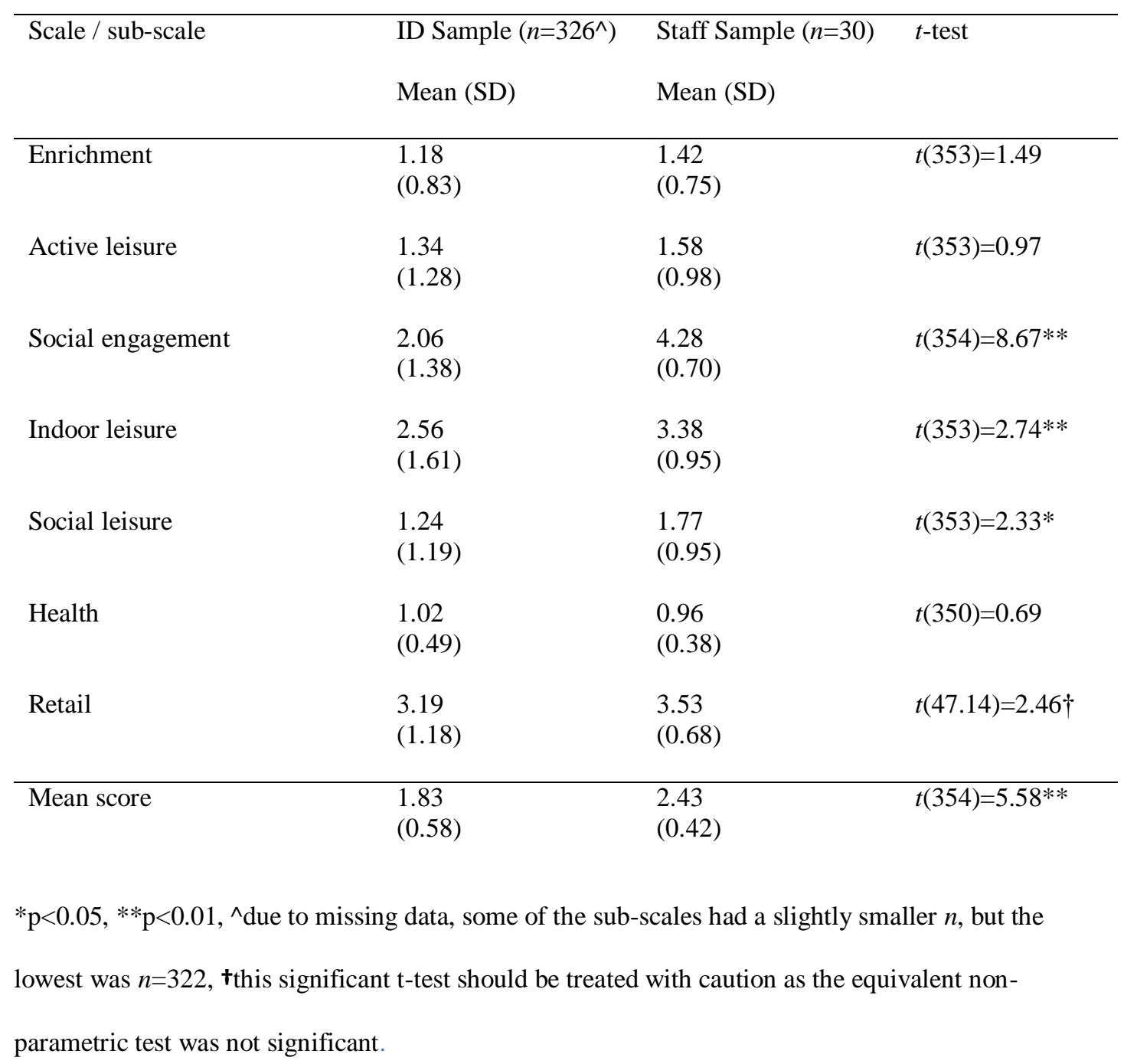




\section{Online Supplementary Material}

Table S1: The mean, SD, range, sample size and percentage of missing data (out of the total sample of 326 participants) for all 46 candidate GCPLA-R items. Items marked with an asterisk were included in the final 23 item version of the GCPLA-R.

\begin{tabular}{|c|c|c|c|c|c|c|}
\hline Item & $\begin{array}{l}\mathrm{n} \text { (not } \\
\text { missing) }\end{array}$ & $\begin{array}{l}\% \\
\text { missing }\end{array}$ & Mean & SD & Minimum & Maximum \\
\hline Doctor (GP)* & 319 & 2.1 & 1.23 & 0.72 & 0 & 3 \\
\hline Dentist* & 313 & 4.0 & 1.07 & 0.54 & 0 & 3 \\
\hline Hospital* & 307 & 5.8 & 0.75 & 0.67 & 0 & 4 \\
\hline Work (paid or voluntary) & 315 & 3.4 & 1.09 & 1.84 & 0 & 5 \\
\hline Adult education/College & 313 & 4.0 & 1.01 & 1.77 & 0 & 5 \\
\hline $\begin{array}{l}\text { Look at books/magazines } \\
\text { etc* }\end{array}$ & 320 & 1.8 & 3.05 & 1.93 & 0 & 5 \\
\hline $\begin{array}{l}\text { Play games/computer } \\
\text { games (with others)* }\end{array}$ & 198 & 39.3 & 2.40 & 1.96 & 0 & 5 \\
\hline $\begin{array}{l}\text { Play games/computer } \\
\text { games (solitary)* }\end{array}$ & 316 & 3.1 & 2.09 & 2.20 & 0 & 5 \\
\hline Watch TV & 324 & 0.6 & 4.42 & 1.40 & 0 & 5 \\
\hline Watch DVD & 324 & 0.6 & 3.68 & 1.56 & 0 & 5 \\
\hline Browse internet* & 320 & 1.8 & 2.22 & 2.25 & 0 & 5 \\
\hline Interact with pets/animals & 320 & 1.8 & 1.95 & 2.05 & 0 & 5 \\
\hline Participate in sports* & 322 & 1.2 & 1.17 & 1.75 & 0 & 5 \\
\hline Spectator sport & 198 & 39.3 & 0.67 & 1.27 & 0 & 5 \\
\hline Exercise/aerobic class* & 315 & 3.4 & 1.22 & 1.83 & 0 & 5 \\
\hline Cycling & 317 & 2.8 & 0.55 & 1.21 & 0 & 5 \\
\hline Listen to music/radio & 320 & 1.8 & 4.04 & 1.57 & 0 & 5 \\
\hline $\begin{array}{l}\text { Participate in performing } \\
\text { arts/music }\end{array}$ & 321 & 1.5 & 1.25 & 1.72 & 0 & 5 \\
\hline Create art/activity & 319 & 2.1 & 2.20 & 1.86 & 0 & 5 \\
\hline $\begin{array}{l}\text { Attend museum/art } \\
\text { gallery* }\end{array}$ & 321 & 1.5 & 0.83 & 1.06 & 0 & 5 \\
\hline $\begin{array}{l}\text { Attend live performing } \\
\text { arts* }\end{array}$ & 319 & 2.1 & 1.11 & 1.08 & 0 & 5 \\
\hline Attend cinema* & 323 & 0.9 & 1.43 & 1.21 & 0 & 5 \\
\hline Go for a walk (local) & 323 & 0.9 & 3.77 & 1.46 & 0 & 5 \\
\hline Outdoor pursuits & 306 & 6.1 & 1.48 & 1.76 & 0 & 5 \\
\hline
\end{tabular}




\begin{tabular}{|c|c|c|c|c|c|c|}
\hline Holiday or daytrip* & 314 & 3.7 & 1.60 & 1.14 & 0 & 5 \\
\hline Swimming* & 317 & 2.8 & 1.67 & 1.75 & 0 & 5 \\
\hline DIY & 317 & 2.8 & 0.27 & 0.83 & 0 & 4 \\
\hline Gardening & 323 & 0.9 & 1.25 & 1.58 & 0 & 5 \\
\hline Disco/nightclub* & 315 & 3.4 & 1.02 & 1.40 & 0 & 5 \\
\hline Pub & 321 & 1.5 & 2.18 & 1.61 & 0 & 5 \\
\hline Restaurant/Café* & 313 & 4.0 & 3.19 & 1.33 & 0 & 5 \\
\hline Go to a friend's house* & 323 & 0.9 & 1.07 & 1.37 & 0 & 5 \\
\hline Spend time with family* & 321 & 1.5 & 3.21 & 1.52 & 0 & 5 \\
\hline Social club/ society* & 314 & 3.7 & 1.58 & 1.82 & 0 & 5 \\
\hline $\begin{array}{l}\text { Social networking via } \\
\text { internet* }\end{array}$ & 323 & 0.9 & 0.77 & 1.65 & 0 & 5 \\
\hline Help others & 315 & 3.4 & 1.76 & 1.99 & 0 & 5 \\
\hline $\begin{array}{l}\text { Citizenship/Political } \\
\text { activity }\end{array}$ & 318 & 2.5 & 0.16 & 0.64 & 0 & 5 \\
\hline Public transport & 324 & 0.6 & 2.73 & 1.78 & 0 & 5 \\
\hline Local shop/Post office* & 321 & 1.5 & 3.22 & 1.68 & 0 & 5 \\
\hline High Street store* & 320 & 1.8 & 2.99 & 1.51 & 0 & 5 \\
\hline $\begin{array}{l}\text { Supermarket/Large retail } \\
\text { outlet* }\end{array}$ & 322 & 1.2 & 3.38 & 1.35 & 0 & 5 \\
\hline Car boot/Jumble sale & 318 & 2.5 & 0.50 & 0.95 & 0 & 5 \\
\hline Hairdresser/Beauty salon & 320 & 1.8 & 1.61 & 1.21 & 0 & 5 \\
\hline Bank/Building Society & 322 & 1.2 & 1.38 & 1.78 & 0 & 5 \\
\hline Place of worship & 323 & 0.9 & 0.54 & 1.14 & 0 & 4 \\
\hline Library & 322 & 1.2 & 0.80 & 1.30 & 0 & 5 \\
\hline
\end{tabular}


Table S2: Content of the two focus group discussions divided into three superordinate themes

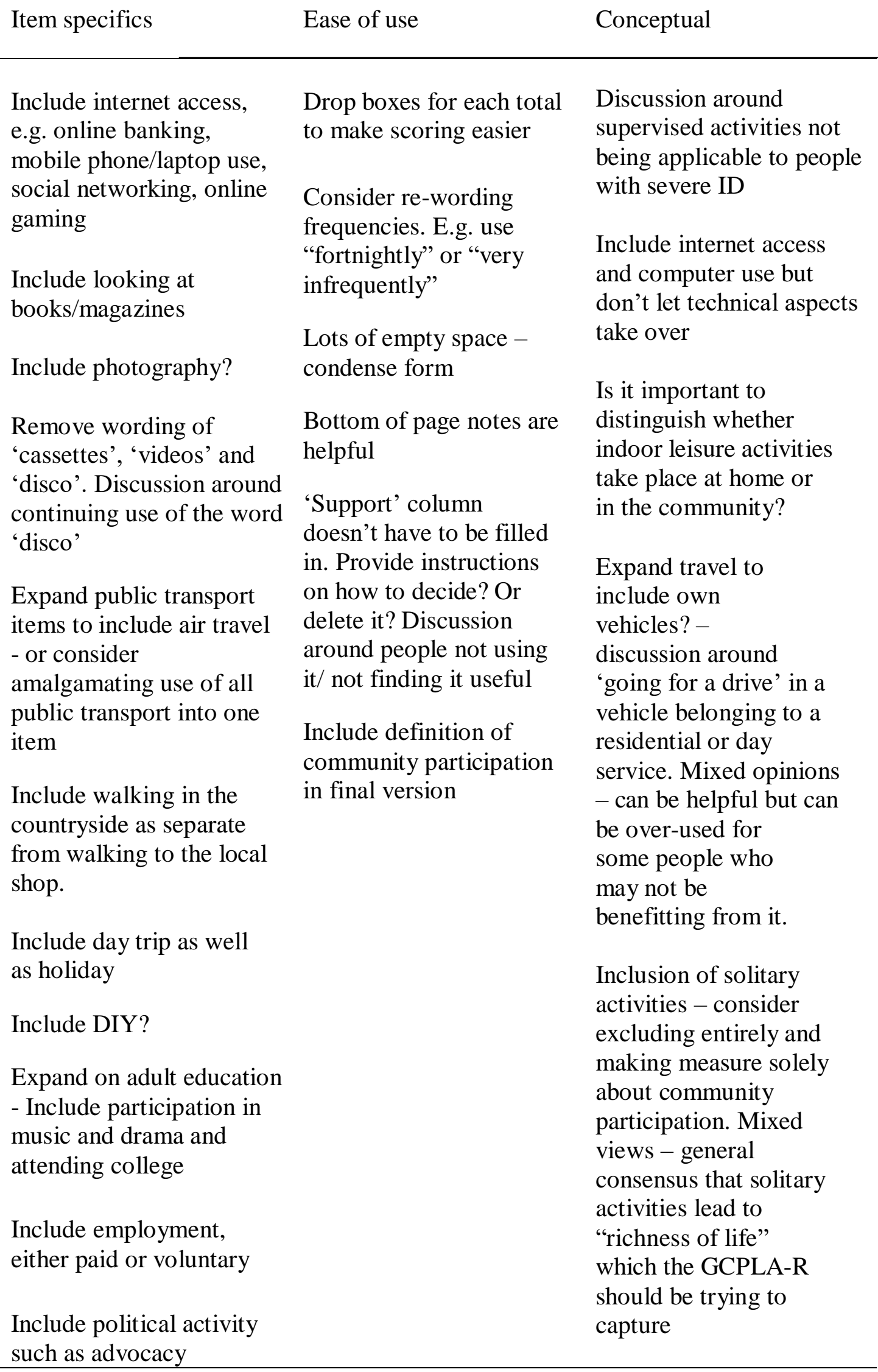




\begin{tabular}{|c|c|}
\hline \\
\hline $\begin{array}{l}\text { involvement or } \\
\text { fundraising }\end{array}$ & $\begin{array}{l}\text { Discussion around } \\
\text { including engagement }\end{array}$ \\
\hline Include assisting others & $\begin{array}{l}\text { in household tasks - } \\
\text { shift towards general } \\
\text { measure of } \\
\text { engagement? }\end{array}$ \\
\hline $\begin{array}{l}\text { Discussion around need } \\
\text { for equilibrium and not } \\
\text { increasing the measure to } \\
\text { include too many items. }\end{array}$ & $\begin{array}{l}\text { It would be helpful to } \\
\text { measure 'active } \\
\text { involvement' and not just } \\
\text { 'passivity' }\end{array}$ \\
\hline $\begin{array}{l}\text { Consider including a box } \\
\text { for 'Other' }\end{array}$ & $\begin{array}{l}\text { Discussion around } \\
\text { whether it matters if } \\
\text { participation is with the } \\
\text { general public or }\end{array}$ \\
\hline Include nightclub. & $\begin{array}{l}\text { exclusively with other } \\
\text { service users. General }\end{array}$ \\
\hline $\begin{array}{l}\text { Discussion around } \\
\text { possible out datedness of } \\
\text { word 'disco' - service }\end{array}$ & $\begin{array}{l}\text { feeling that 'segregated' } \\
\text { activities are of worth as } \\
\text { well as unsegregated. }\end{array}$ \\
\hline $\begin{array}{l}\text { users expressed the } \\
\text { view that this word is } \\
\text { still current and should } \\
\text { be included. }\end{array}$ & $\begin{array}{l}\text { Have space on the } \\
\text { GCPLA-R to record } \\
\text { what an individual's } \\
\text { favourite activities are in }\end{array}$ \\
\hline $\begin{array}{l}\text { Where would 'music } \\
\text { festival' fit? Consider re- }\end{array}$ & $\begin{array}{l}\text { order to measure } \\
\text { participation in these }\end{array}$ \\
\hline $\begin{array}{l}\text { Remove 'go to } \\
\text { neighbour's house' }\end{array}$ & $\begin{array}{l}\text { Consider incorporating a } \\
\text { 'choice' box to indicate } \\
\text { whether an activity was } \\
\text { participated in by choice. }\end{array}$ \\
\hline $\begin{array}{l}\text { Include 'Attend } \\
\text { reviews'? Mixed views } \\
\text { on this }\end{array}$ & $\begin{array}{l}\text { Discussion around current } \\
\text { measures used to measure } \\
\text { choice alongside GCPLA } \\
\text { and possible over- } \\
\text { complication of GCPLA- } \\
\text { R. }\end{array}$ \\
\hline & $\begin{array}{l}\text { Discussion around } \\
\text { subjective nature of } \\
\text { measuring somebody's } \\
\text { choice by proxy and } \\
\text { subsequent validity of this }\end{array}$ \\
\hline Consider including & $\begin{array}{l}\text { Discussion around } \\
\text { whether some staff and }\end{array}$ \\
\hline
\end{tabular}




\begin{tabular}{|c|c|}
\hline $\begin{array}{l}\text { 'Contact with } \\
\text { professionals' such as } \\
\text { social workers, } \\
\text { osteopaths and } \\
\text { chiropodists. Mixed } \\
\text { views on this. }\end{array}$ & $\begin{array}{l}\text { service users may } \\
\text { consider the GCPLA a } \\
\text { test rather than a } \\
\text { measure. Consider } \\
\text { including a small } \\
\text { explanation of the } \\
\text { GCPLA-R as a measure } \\
\text { and not a test } \\
\text { Consider developing a } \\
\text { parallel measure to be } \\
\text { used by individuals with } \\
\text { ID rather than by proxy } \\
\text { Include a 'Planning' box } \\
\text { for clinical needs - to } \\
\text { bridge the gap between } \\
\text { the GCPLA-R and } \\
\text { action points } \\
\text { GCPLA is a useful tool } \\
\text { for facilitating reflective } \\
\text { practice } \\
\text { Discussion around } \\
\text { whether it should 'count' } \\
\text { when a hairdresser or } \\
\text { doctor visits the home. } \\
\text { Mixed views. Consider } \\
\text { rewording and } \\
\text { combining items to } \\
\text { create "accessing } \\
\text { medical professionals"? } \\
\text { Discussion around } \\
\text { whether it should be } \\
\text { recorded how many } \\
\text { activities were } \\
\text { accessed through day } \\
\text { services. Mixed views } \\
\text { on this. }\end{array}$ \\
\hline
\end{tabular}




\section{The Guernsey Community Participation and Leisure Assessment - Revised}

Baker, Taylor-Roberts \& Jones (2020)

Please indicate, by a tick in the appropriate box, the frequency with which the focal person does the following activities. See definitions. Upon completion summate the scores on each item and record in the scoring box

\begin{tabular}{|c|c|c|c|c|c|c|}
\hline ACTIVITY & 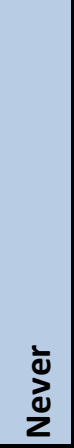 & 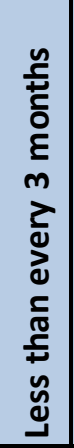 & 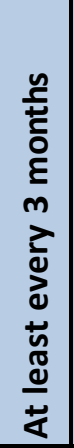 & 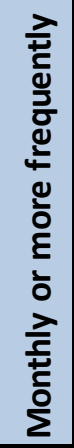 & 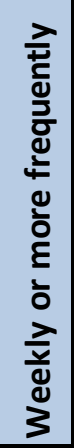 & 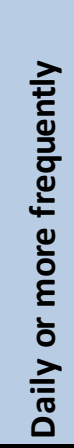 \\
\hline & 0 & 1 & 2 & 3 & 4 & 5 \\
\hline \multicolumn{7}{|l|}{ Enrichment } \\
\hline \multicolumn{7}{|c|}{ Attend museum/art gallery } \\
\hline \multicolumn{7}{|c|}{ Attend live performing arts } \\
\hline \multicolumn{7}{|l|}{ Holiday or daytrip } \\
\hline \multicolumn{7}{|l|}{ Active Leisure } \\
\hline \multicolumn{7}{|l|}{ Swimming } \\
\hline \multicolumn{7}{|l|}{ Participate in Sport } \\
\hline \multicolumn{7}{|l|}{ Exercise/Areobics class } \\
\hline \multicolumn{7}{|c|}{ Participate performing arts/music } \\
\hline \multicolumn{7}{|l|}{ Social Engagement } \\
\hline \multicolumn{7}{|c|}{ Social networking via the internet } \\
\hline \multicolumn{7}{|l|}{ Browse internet } \\
\hline \multicolumn{7}{|l|}{ Spend time with family } \\
\hline \multicolumn{7}{|l|}{ Indoor leisure } \\
\hline \multicolumn{7}{|l|}{ Play games with others } \\
\hline \multicolumn{7}{|c|}{ Look at books/magazines } \\
\hline \multicolumn{7}{|l|}{ Social Leisure } \\
\hline \multicolumn{7}{|l|}{ Social club/society } \\
\hline \multicolumn{7}{|l|}{ Disco/nightclub } \\
\hline \multicolumn{7}{|l|}{ Go to a friends house } \\
\hline \multicolumn{7}{|l|}{ Health } \\
\hline \multicolumn{7}{|l|}{ Hosptial } \\
\hline \multicolumn{7}{|l|}{ Doctor (GP) } \\
\hline \multicolumn{7}{|l|}{ Dentist } \\
\hline \multicolumn{7}{|l|}{ Retail } \\
\hline \multicolumn{7}{|l|}{ High Street store } \\
\hline \multicolumn{7}{|c|}{ Supermarket/large retail outlet } \\
\hline \multicolumn{7}{|l|}{ Local shop/post office } \\
\hline Restaurant/café & & & & & & \\
\hline
\end{tabular}

Name of Focal Person:

Date:

Who is completing this form:

\begin{tabular}{|l|l|}
\hline Subscale & Score \\
\hline Enrichment & \\
\hline Active Leisure & \\
\hline Social Engagement & \\
\hline Indoor Leisure & \\
\hline Social Leisure & \\
\hline Health & \\
\hline Retail & \\
\hline Total & \\
\hline
\end{tabular}

(C) Tizard Centre 


\begin{tabular}{|c|c|}
\hline \multicolumn{2}{|l|}{ Enrichment } \\
\hline Attend museum/art gallery & $\begin{array}{l}\text { To attend by choice a display of objects for historic, } \\
\text { cultural, scientific or artistic interest }\end{array}$ \\
\hline Attend live performing arts & $\begin{array}{l}\text { To visit by choice a public site to actively watch an } \\
\text { organised music/ drama/ comedy performance. }\end{array}$ \\
\hline Holiday or daytrip & $\begin{array}{l}\text { To experience an extended period of recreation away } \\
\text { from home. }\end{array}$ \\
\hline \multicolumn{2}{|l|}{ Active Leisure } \\
\hline Swimming & To swim in a pool or the sea. \\
\hline Participate in Sport & $\begin{array}{l}\text { To actively participate in a team game or competitive } \\
\text { activity either indoors or outdoors. Not including } \\
\text { swimming. }\end{array}$ \\
\hline Exercise/Aerobics class & $\begin{array}{l}\text { To actively participate by choice in an organised } \\
\text { exercise session involving physical exercise to sustain } \\
\text { health or improve fitness. }\end{array}$ \\
\hline Participate performing arts/music & $\begin{array}{l}\text { To actively participate in a music/ drama/ live } \\
\text { comedy either for recreational or educational } \\
\text { purposes. }\end{array}$ \\
\hline \multicolumn{2}{|l|}{ Social Engagement } \\
\hline Social networking via the internet & $\begin{array}{l}\text { To purposefully use the internet for socialising, e.g. } \\
\text { Facebook, Twitter, Instagram or dating websites }\end{array}$ \\
\hline Browse internet & $\begin{array}{l}\text { To purposefully use the internet to shop/ research } \\
\text { topics/ access services/ look at images or videos. Not } \\
\text { including social networking. }\end{array}$ \\
\hline Spend time with family & To spend time with family members. \\
\hline \multicolumn{2}{|l|}{ Indoor leisure } \\
\hline Play games with others & $\begin{array}{l}\text { To actively participate in a game with formal rules, } \\
\text { including online gaming. Not including sport or } \\
\text { informal ball games. }\end{array}$ \\
\hline Look at books/magazines & $\begin{array}{l}\text { To actively spend time looking at books or } \\
\text { magazines. }\end{array}$ \\
\hline \multicolumn{2}{|l|}{ Social Leisure } \\
\hline Social club/society & $\begin{array}{l}\text { To attend by choice a venue used for a formal } \\
\text { association/gathering of people with similar interests. }\end{array}$ \\
\hline Nightclub & $\begin{array}{l}\text { To attend by choice a public or organised event at a } \\
\text { site used to dance/listen to recorded music (not } \\
\text { including live concerts). }\end{array}$ \\
\hline Go to a friend's house & $\begin{array}{l}\text { To go to the home of a person liked by the individual } \\
\text { who is not a relative or current paid staff. }\end{array}$ \\
\hline \multicolumn{2}{|l|}{ Health } \\
\hline Hospital & To visit a hospital either as a patient or visitor. \\
\hline Doctor (GP) & A medical doctor working in the community. \\
\hline Dentist & A dentist or hygienist in the community. \\
\hline \multicolumn{2}{|l|}{ Retail } \\
\hline High Street store & $\begin{array}{l}\text { To go by choice to a department store or other shops } \\
\text { in a town centre or shopping complex. }\end{array}$ \\
\hline Supermarket/large retail outlet & $\begin{array}{l}\text { To go by choice to a large retail outlet (e.g. out of } \\
\text { town store, garden centre) or a large store selling } \\
\text { household goods and groceries. }\end{array}$ \\
\hline Local shop/post office & To go by choice to a local shop or post office \\
\hline
\end{tabular}

